\title{
Use of the Ottawa ankle rules by nurse practitioners
}

\author{
C J Mann, I Grant, H Guly, P Hughes
}

\begin{abstract}
Objective-To determine the ability of nurse practitioners to use the Ottawa ankle rules by comparing their requests for radiography with those of senior house officers (SHOs).

Method-1365 patients were assessed by a nurse trained in the use of the Ottawa ankle rules. Where indicated the nurse sent the patient for radiography. 700 patients in the same period were seen by SHOs who had not received training in these rules. After three months the SHOs were similarly trained in the use of the rules and a further 700 patients were seen. Results-Nurse practitioners assessed 1365 patients; $72.6 \%$ had radiography. 1398 patients were seen only by an SHO. Before their use of the Ottawa ankle rules SHOs requested radiography in $91.0 \%(p=0.001)$; using the rules this fell to $74.2 \%(p=0.001)$. Conclusion-Nurse practitioners trained to use the Ottawa ankle rules are as effective as SHOs in the implementation of the rules. Moreover the sensitivity and specificity of the Ottawa ankle rules was similar to that seen in other studies. $(\Im$ Accid Emerg Med 1998;15:315-316)
\end{abstract}

Keywords: Ottawa ankle rules; nurse practitioner; ankle fracture

Sprains of the ankle are one of the commonest injuries seen in the accident and emergency (A\&E) department. Much research has been done to assess the clinical features that indicate an underlying fracture and thereby reduce the number of radiographs taken. The current Ottawa ankle rules were published in 1993. The aim was to produce guidelines for the radiography of ankle injuries that were $100 \%$ sensitive for ankle fractures. The study produced rules whereby the decision to radiograph an ankle was formalised on the basis of three key clinical findings':

(1) Bony tenderness along posterior edge of lower $6 \mathrm{~cm}$ of fibula or tip of lateral malleolus;

(2) Bony tenderness along posterior edge of lower $6 \mathrm{~cm}$ of tibia or tip of medial malleolus;

(3) Inability to bear weight (walk four consecutive steps) both immediately and in the emergency department.

These rules were applied only to patients over 16.

The introduction of these rules in the original study department reduced radiography of the ankle by $34 \%$. The rules were found to have a sensitivity of 1.0 and a specificity of 0.49 . $^{2}$ Several follow up studies have confirmed these findings. ${ }^{2-4}$ Another study, although unable to demonstrate such a high level of sensitivity, did demonstrate the rules to be better than clinical suspicion alone. ${ }^{5}$

In the UK there has been an increase in the use of nurse practitioners both in minor injury units and major A\&E departments. ${ }^{6}$ Several allow trained nurse practitioners to request radiography. ${ }^{7}$ One study suggested that nurse practitioners tend to order more radiographs than senior house officers (SHOs). ${ }^{6}$ However in this study most of the nurses had not received specific training in when to request radiography.

This study assesses the use of the Ottawa ankle rules by nurse practitioners and compares the outcome of their practice with that of SHOs.

\section{Method}

A total of 2763 patients over 16 years of age presenting within 24 hours of an acute, closed, isolated ankle injury were entered into the study.

The study population was divided into three groups. Group 1 (1365 patients) was assessed by nurse practitioners trained in the use of the Ottawa ankle rules and sent for a radiograph when indicated by the rules. All patients were subsequently examined by an SHO and a radiograph ordered if the SHO felt this to be appropriate. Group 2 (698 patients) was assessed by SHOs with no formal training in the use of these rules. Group 3 (700 patients) was assessed by the same SHOs after formal introduction of the Ottawa ankle rules.

The results were tested using $\chi^{2}$ analysis.

To determine the incidence of fractures missed because of failure to take a radiograph, any reattendances to the $A \& E$ department within a four week period either initiated by the patient or as a result of a general practitioner referral, were reviewed to identify if a fracture was later confirmed. In the hospital studied there is no access to the fracture clinic except via the $A \& E$ department.

Fractures were identified by SHOs in the A\&E department and subsequently the diagnosis was confirmed by radiologists. Where there was disagreement the radiology opinion was taken as the reference opinion.

\section{Results}

Table 1 demonstrates the number of patients who had radiographs taken and the number with identified fractures in each group.

Significantly fewer radiographs were requested by both nurse practitioners and SHOs using the Ottawa ankle rules compared with 
Table 1

\begin{tabular}{lcll}
\hline & Patients & Radiographs (\%) & Fractures (\%) \\
\hline Group 1 & 1365 & $991(73)$ & $237(24)$ \\
Group 2 & 698 & $637(91)$ & $133(20)$ \\
Group 3 & 700 & $519(74)$ & $127(24)$ \\
\hline
\end{tabular}

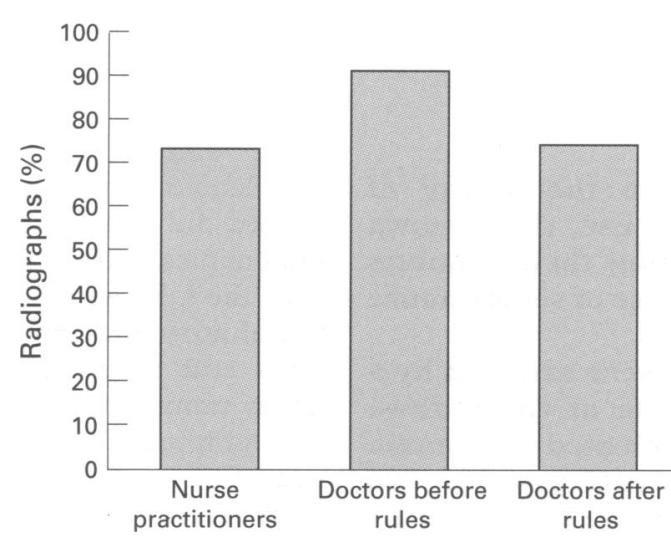

Figure 1 Radiographs requested by nurse practitioners and SHOs.

Table 2 Fractures missed because of failure to request radiography

\begin{tabular}{lll}
\hline Fracture & Nurse practitioners & SHOs \\
\hline Avulsion, lateral malleolus & 3 & 3 \\
Avulsion, medial malleolus & 1 & - \\
Avulsion, talus & 1 & 1 \\
\hline
\end{tabular}

SHOs not using the Ottawa ankle rules ( $\mathrm{p}=$ 0.001 ; fig 1). There was no significant difference in those sent for radiography by SHOs or nurses using the Ottawa ankle rules.

In group 1, 64 patients were not sent for radiography by the nurse practitioners $(4.7 \%)$ but were by the A\&E SHO; none of these had a fracture.

There was no significant difference in the number of fractures seen in the three groups.

Thirty of the patients not sent for radiography reattended $(5 \%)$; all then had radiographs taken. Five minor fractures were missed in group 1, two in group 2, and two in group 3 (not significant; table 2). A minor fracture was defined as requiring no immobilisation or fixation, requiring only such treatment as used for a sprained ankle.

The sensitivity of the Ottawa ankle rules when used by trained nurse practitioners was 0.98 with a specificity of 0.32 . When used by SHOs the sensitivity was 0.98 and the specificity 0.28 . The sensitivity for both groups in detecting fractures greater than $3 \mathrm{~mm}$ was 1.0 .

\section{Discussion}

Nurse practitioners trained to use the Ottawa ankle rules can accurately determine which patients require a radiograph of the ankle. The sensitivity and specificity demonstrated compares well with other studies. ${ }^{245}$

Although the SHOs were not initially taught to use the Ottawa rules they could not be truly blinded, either to their existence or their use by nurse practitioners. However awareness of them would be expected to reduce the rate of ankle radiography and therefore diminish rather than exaggerate the difference seen between the two groups.

The fall in the rate of ankle radiology requested by SHOs might be a function of experience. However this effect was not demonstrated when analysis was made of radiology requests by SHOs for the previous two years (unpublished internal audit) and therefore seems unlikely.

The method used to detect missed fractures would not include any fracture diagnosed at another hospital. Although this department is the only $A \& E$ department serving a catchment population of 410000 , there are a large number of tourists to the region served, who may therefore have presented elsewhere.

The use of the Ottawa ankle rules by nurse practitioners and SHOs reduced the rate of ankle radiography by $20 \%$. This matches the reduction in radiography requests seen in other studies, ${ }^{2-4}$ and has significant implications for cost saving both in raw materials and reporting time. In the United States this reduction in costs has been estimated at between $\$ 6$ and $\$ 30$ per patient. $^{8}$ In the department studied it would produce a cost saving of $£ 4.66$ per ankle injury patient.

Waiting times have previously been shown to be reduced both in departments using the Ottawa ankle rules ${ }^{2}$ and in departments using nurse practitioners, ${ }^{67}$ and the Audit Commission has advocated the expansion of nursing assessment to include the requesting of routine radiography. ${ }^{9}$

\section{Conclusion}

This study demonstrates that with training the scope of practice for nurse practitioners can be increased to include the use of the Ottawa ankle rules to request ankle radiographs with benefits to patients, SHOs, and health care purchasers.

1 Stiell IG, Greenberg GH, Mc Knight RD, et al. Decision rules for the use of radiography in acute ankle injuries JAMA 1993;269:1127-32.

2 Stiell IG, Greenberg GH, Mc Knight RD, et al. Implementation of the Ottawa ankle rules. JAMA 1994;271:827-32.

3 Stiell IG,Greenberg GH, Mc Knight RD, et al. Multicentre trial to introduce the Ottawa ankle rules for use of radiography in acute ankle injuries. BMJ 1995;311:594-6.

4 Pigman EC, Klug RK, Sanford S, et al. Evaluation of the Ottawa clinical decision rules for the use of radiography in acute ankle and midfoot injuries in the emergency acute ankle and midfoot injuries in the emergency Med 1994;24:41-5.

5 Lucchesi GM, Jackson RE, Peacock WF, et al. Sensitivity of the Ottawa rules. Ann Emerg Med 1995;26:1-5.

6 Thurston J, Field S. Should accident and emergency nurses request radiographs? Results of a multicentre evaluation. J
Accid Emerg Med 1996;13:86-9.

7 Baker B. Model methods. Nursing Times 1993;89(47).

8 Anis AH, Stiell IG, Stewart DG, et al. Cost effectiveness analysis of the Ottawa ankle rules. Ann Emerg Med 1995; analysis of

9 Audit Commission. By accident or design: improving $A \mathcal{E} E$ services in England and Wales. London: HMSO, 1996. 